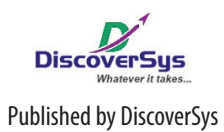

Published by DiscoverSys

\section{Policy for Drug Users in Indonesia: A Critical Policy Analysis of Jail Punishment and an Alternate Rehabilitation Policy}

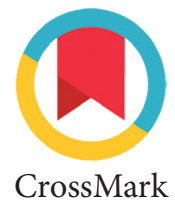

\author{
I Nyoman Sutarsa*
}

Department of Community and Preventive Medicine, Faculty of Medicine Udayana University
*Correspondence to: I Nyoman Sutarsa, Department of Community and Preventive Medicine, Faculty of Medicine Udayana University sutarsa84@gmail.com

\section{INTRODUCTION}

The prevalence of drug users in Indonesia during 2004 was $1.5 \%$ from a total population (3.2 million people). About $69 \%$ of them were abusers and $31 \%$ were addicted. In addition, $6 \%$ of the total population have experienced drugs. ${ }^{1}$ Illicit drugs are harming people in many ways, causing a wide range of health problems: addiction, injuries, cardiovascular diseases, HIV/AIDS, hepatitis and cancers. One in five drug users meet the WHO criteria for dependence. ${ }^{2}$

Illicit drugs alter brain function and mood/ perception, generate psychological and psychosocial problems, employment loss, legal issues, homelessness, family disruptions, loss of economic productivity, social instability, criminality and difficulty in academic participation. ${ }^{2,3}$ Globally, drug abuse kills 4 people per 100,000 people and $2-3 \%$ of opioid users die every year due to overdose. ${ }^{2,3}$ Furthermore, alcohol and drug abuse contribute as many as $5.4 \%$ of the global annual disease burden (in comparison to only 3.7\% from tobacco). ${ }^{2}$ Drug abuse also contributes to HIV transmission (5-10\%), hepatitis C (50-85\%) and liver cancer $(7-15 \%){ }^{3}$ Drug abuse is identified as a significant contributing factor for mental health problems. ${ }^{2,4}$ In the end, drug abuse leads to increased national burdens (economic, health, and social) and reduced quality of life for individuals. It also alters social function of individuals at family or community levels, resulting in economic productivity loss.

Drug abuse in Indonesia is a complex problem and influenced by many determinants. Increasing cost of living, absence of income generation and less job opportunities are crucial and might trigger people to sell drugs. Poverty together with limited growth of informal economies and economic uncertainty are also enabling factors of selling drugs. ${ }^{5}$ Moreover, open international access through trading and tourism industries contribute significantly to drug supply. In relation to reducing harms, cost of health treatments, cost of prevention materials, limited community health and welfare service access, stigmatisation or marginalisation and weak civil society or community advocacy are major challenges. ${ }^{5}$ Furthermore, policy environment is crucial including laws governing protection of human and health rights, laws governing possession of drugs and public health policy governing harm reduction and drug treatment. $^{5}$

There are two main approaches to address the issue of drug users: law and humanitarian. Law approach views drug users as criminals and jailing is the way to solve the problem while humanitarian approach views them as victims who need assistance and rehabilitation to address the problem. Criminalising drug users is common practice in some countries such as Indonesia and Vietnam. However, based on a health perspective, ICD 10 section $\mathrm{F}$ defines drug users as having a mental disorder needing clinical and social rehabilitation. Jailing people in need of health care instead of rehabilitation is another form of human right violation. The Indonesian government responded to the increasing trend of drug users by criminalising them as stated in The Anti-Narcotic Bill No 22/1997 and The Psychotropic Bill No 5/1997. These are not statements of war against drugs, but more likely war on people who are using drugs. The production of and the distribution activities of drugs are criminal. However, criminalisation of drug users as a form of 'demand reduction' brings serious threat to public health in Indonesia. Alternate options are crucial to prevent further harms from jail punishment.

\section{DISCUSSION}

\section{Drug user policy in Indonesia: who will play what parts?}

Illicit drugs are a complex problem and many stakeholders are involved in addressing them. The identification of the policy players is an essential component of policy analysis - where each actor emerges with specific roles and interest. ${ }^{6}$ Firstly, National Drugs Body (Badan Narkotika Nasional/ BNN) is the national body that plays a major role in overcoming this problem in Indonesia. However, $\mathrm{BNN}$ is no longer operating as the national coordination body, but rather BNN now acts more like a functional body delivering activities - equivalent to other government departments (health, social welfare, law and human rights). Given this fact, the activities among various 
stakeholders are less coordinated. Furthermore, budget allocation is imbalanced. Most of the budget is allocated to $\mathrm{BNN}$, resulting in significantly reduced budget allocation and programmes in the health and social-welfare sectors. Moreover, there is no clear statement about which department or body will be responsible for health and social impacts related to drug users.

Ideally, different actors should have specific objectives or responsibilities and maintain coordinated partnership with other interested stakeholders to meet larger goals. In relation to drug user policy in Indonesia, there are at least 8 major actors to be involved: BNN, Department of Law and Human Right, Department of Health, Department of Social Welfare, National AIDS Commission (Komisi Penanggulangan AIDS Nasional or KPA), Non Government Organisations, Private Sector and Community. The government will provide budget and BNN plays role as the coordination body. Department of Justice and Human Rights is mainly responsible for issues related to drugs production and supply as well as case confirmation. Department of Health is responsible for providing clinical rehabilitation and prevention measures to reduce harms. Department of Social Welfare's main duties are providing social and family rehabilitation, including stigma reduction and re-integration measures. KPA acts as the coordination body for HIV related to drugs (mainly among Injecting Drug Users/IDUs and their sexual behaviour). Strategic partnership should be built up with NGOs, private sector and community.

\section{The opportunity for rehabilitation policy}

Drug control in Indonesia was formally started in 1971 by the release of President Instruction No 6/1971 towards the National Coordination Intelligent Body (BAKIN). The first coordination task force built in 1971 consisted of several stakeholders including health, social welfare, foreign affairs, justice and human rights. BAKIN acted as the coordination body, not subjected to operational responsibilities. No specific additional budget was allocated to BAKIN. During 1971, drugs were not assumed as a great threat. President Soeharto's government believed that a drugs problem would not emerge because of national value systems, religious values and social values against drugs. This situation correlates with Dye's statement (cited in Colebatch 1998) that 'policy is whatever governments choose to do or not to do'. Given the government's position, it is not surprising it was almost impossible for legislative changes or other institutions to influence executive decisions on drugs policy during this period. This reflects the fact that authority played the major role in policy making for this situation. Soeharto, who had a military background, was a president with a strong authority from $1966-1997 / 98 .^{7}$ As a result, by the middle of 1997, Indonesia was hit by a big illicit drugs problem in parallel with financial crisis. In response to this problem, the government and legislative agreed to enact Indonesian Anti-Narcotic Bill No. 5/1997 and Indonesian Psychotropic Bill No. 22/1997.

Based on those two bills, the government of Soeharto's successor President Wahid released President Instruction No. 116/1999. This developed the National Narcotic Coordination Body (NNCB), drawing on resources from 25 related inter-governmental departments. The NNCB was headed by the police and was funded by the Police Department from 2002. During this period, the function of the NNCB was influenced by the interest of police as a stakeholder of drugs control in Indonesia. This condition triggered the release of President Instruction No. 17/2002 and changed the NNCB to the National Drugs Body (BNN), acting as both a coordination and operational body. BNN was funded directly by government through the national budget starting from 2003.

The epidemic of HIV/AIDS in Indonesia started in 1987 and first reported cases among IDUs was in 1995. Since then, IDUs were identified as the major route of HIV transmission in Indonesia. The total HIV/AIDS cases doubled by $2003 / 2004$ and $80 \%$ of total new cases were IDUs. ${ }^{8}$ This fact opened the window for health stakeholder perspectives to be more influential in policy making process, especially related to risk reduction, having more power to influence context, process, and content of policy as well as competing interest with competing demand. ${ }^{6,9,10}$

Several international and national policy perspectives support the position advocated by health and social stakeholders in Indonesia. WHO (1995) recommend risk reduction as the critical solution for IDUs. ${ }^{11}$ Moreover, The National AIDS Commission (KPA) was established following the pandemic of HIV/AIDS in Indonesia. Both KPA and the health sector are strongly interested in 'harm reduction policy' rather than 'supply and demand reduction'. WHO (1995) ${ }^{11}$ emphasised the need to shift commitment from a law approach and focus more on public health and social issues related to drug users. Research from WHO (1995) ${ }^{11}$ stated that expansion of drug user treatment, substitution therapy, in patient detoxification and rehabilitation services significantly reduce the prevalence of HIV/AIDS transmission globally. However, in Indonesia there are less national policies to handle these measures. Law approach through jail punishment 
needs to shift to a humanitarian approach. Treating drug users as a health issue is critical. Putting drug users at rehabilitation rather than in jail will reduce their risk of having HIV and reduce their risk of converting from oral to injecting users. Humanitarian approach also aims to reduce stigma, increase recovery opportunities and enable re-integration of drug users into community. ${ }^{12}$ These circumstances open more opportunities for health and social sectors to get involved in the policy making process related to drug users and advocate rehabilitation policy. This policy is in line with a $\mathrm{WHO}^{2}$ recommendation to close the gaps for treatment and rehabilitation of drug users. $\mathrm{WHO}^{3}$ stated that 'government need to invest financially and dedicate staffing to provide effective services to treat drug user disorder'.

\section{Jail punishment policy: health and social criticism}

The criminalisation of drug users and putting them in jail as a form of 'demand reduction' could deter people from using drugs. On the other hand, jail punishment can be a serious threat to public health. Firstly, this will discourage drug users to access health services due to fear of disclosing their drug using status. They will be harder to reach by public health intervention strategies such as needle syringe program, substitution therapy program and other harm reduction measures. ${ }^{13}$ Moreover, imprisonment may potentially lead drug users to higher addiction level or converting from oral users to injection users. They also may get more exposure to high risk behaviour such as unsafe injecting and sexual practices that lead to disease transmission including HIV/AIDS, hepatitis $\mathrm{C}$ and sexually transmitted infections (STIs). ${ }^{13}$ Given these facts, jail punishment for drug users could escalate the HIV epidemic; the incidence of blood borne viruses such as hepatitis $\mathrm{C}$ and $\mathrm{B}$; and also death due to overdose. Jail punishment will worsen current stigma and widen discrimination towards drug users which can deteriorate their physical and mental conditions either directly or indirectly. This circumstance will generate difficulty to re-integrate which leads to social dysfunction and potentially reduces their quality of life and productivity.

Jail punishment for drug users could be chosen because it is cheap in the short term, however the long term impacts are more expensive. High quality critical review evidence suggests that jailing has not produced significant benefits. ${ }^{13}$ Furthermore, jail punishment increases burden on the justice system, which is already overwhelmed by many other criminal issues. In fact, one third of people imprisoned globally are due to drug related offences. ${ }^{3}$ According to Department of Justice and Human Right, in 2006 almost 30\% of imprisoned people in Indonesia were drug users. Under the jail punishment policy, more drug users will be jailed, as a result more resources will be spent on drug enforcement activities and less for other drug prevention measures including less funding for rehabilitation programs which are really crucial for drug users. Considering above potential economic, health, and social impacts of jail punishment for drug users, re-evaluating this policy is critical and consideration of alternate policy options is urgently needed.

\section{CONCLUSION}

Criminalisation of drug users and putting them in jail is not the best policy option. Providing rehabilitation (both clinical and social) is more constructive as this will potentially prevent them from exposure to additional harm effects. Social rehabilitation consists of family rehabilitation, community rehabilitation, replacing stigma and re-integration strategies. Rehabilitation policy will directly impact the physical and mental health of the drug users themselves, but this also brings significant impacts at family, community and national levels. A coordination body and clear responsibilities within related stakeholder are vital. Health and social impacts of drug users should be the responsibility of health and social welfare departments.

Given the fact that drug use is a complex problem, public intervention to change and address its determinants are crucial. Social and economic capitals should be channelled via several options, ranging from 'pro to the poor' policy, micro economic enterprise, diversion from informal economy, community engagement, social health insurance for poor people, economic development strategy for community and national level and employment initiatives or providing wider access for job opportunity. National public health policy strategies regarding drug user treatment are also necessary to facilitate future interventions.

\section{REFERENCES}

1. BNN. Statistic 2010. Available from: http://www.bnn.go.id/ portal/index.php/konten/detail/bnn-pusat/profil/8005/ sejarah-bnn

2. WHO. ATLAS 2010. First Global Report on Substance Use Disorder. 2010. Available from: http://www.who.int/ substance_abuse/publications/

3. WHO. WHO/UNODC/UNAIDS Position Paper: Substitution Maintenance Therapy in the Management of Opioid Dependence and HIV/AIDS Prevention. 2004. Available from: http://www. who.int/substance_abuse/ publications/en/PositionPaper_English.pdf 
4. WHO. WHO Mental Health Gap Action Programme. 2010. Available from: http://www. who.int/mental_health/ mhgap/en/index.html

5. Degenhardt L, Mathers B, Vickerman P, Rhodes T, Latkin C, and Hickman M. Prevention of HIV infection for people who inject drugs: why individual, structural, and combination approaches are needed. The Lancet Series 2010: HIV in People Who Use Drugs 2; Vol. 376.

6. Barraclough S. and Gardner H. Analysing Health Policy: A Problem-Oriented Approach. Sydney: Elseiver; 2008.

7. Elson RE. Soeharto: A Political Biography. Cambridge University Press; 2001.

8. Mesquita F, Winarso I, Atmosukarto II, Eka B, Nevendorff L, Rahmah A, Handoyo P, Anastasia P, Angela R. Public Health the leading force of the Indonesian response to the HIV/AIDS crisis among people who inject. Harm Reduction Journal 2007; 4(9)

9. Buse K, Mays N, Walt G. Making Health Policy. Open University Press; 2005.
10. Palmer G and Short S. Health Care and Public Policy: An Australian Analysis $3^{\text {rd }}$ Edition. Melbourne: Macmillan; 2000.

11. WHO. Programme on Substance Abuse: Multi City Study on Drug Injecting and Risk of HIV Infection. 1995. Available from: http://whqlibdoc.who.int/ hq/1994/ WHOPSA94.4.pdf.

12. WHO. UNODC-WHO Programme on Drug Dependence Treatment and Care. 2009. Available from: http://www. who.int/substance_abuse/ activities/unodc_who/en/

13. Jurgens R, Csete J, Amon JJ, Baral S, and Beyrer C. People who use drugs, HIV, and human rights. The Lancet Series 2010; 6(376)

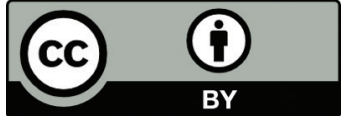

This work is licensed under a Creative Commons Attribution 